\title{
Efeito de leguminosas nas características químicas e matéria orgânica de um solo degradado
}

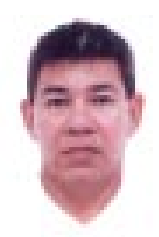

\author{
João T. Nascimento ${ }^{1}$, Ivandro de F. da Silva ${ }^{2}$, Robeval D. Santiago ${ }^{2}$ \& Luiz de F. da Silva Neto ${ }^{2}$
}

1 Esc. Agrot. Fed. de Castanhal, PA. Alameda Padre Rolim, 124, CEP 68743-580, Castanhal, PA. Fone: (91) 3721-6974.

E-mail: jnascimenton@bol.com.br (Foto)

${ }^{2}$ CCA/UFPB/DSER. CEP 58397-000, Areia, PB. Fone: (83) 362-2300

Protocolo 200 - 30/12/2002 - Aprovado em 22/10/2003

\begin{abstract}
Resumo: Com a finalidade de avaliar o efeito de leguminosas nas características químicas de um Luvissolo degradado instalou-se, no município de Alagoinha, PB, um experimento, de 1997-99, com doze espécies: crotalária (Crotalaria juncea, L), guandu (Cajanus cajan,L), guandu-anão (Cajanus cajan (L) Millsp), calopogônio (Calopogonium mucunoides, L), feijão-de-porco (Canavalia ensiforme, L), lab-lab (Dolichos lab lab, L), kudzu tropical (Pueraria phaseoloides, L), siratro (Macroptilium atropurpureum, L), leucena (Leucaena leucocephala, L), cunhã (Clitoria ternatea, L), mucuna preta (Styzolobium aterrimum, L) e mucuna cinza (Styzolobium cinereum Piper e Tracy) além do tratamento testemunha. Nesse estudo, o solo do experimento não recebeu adubo mineral nem corretivo. Avaliaram-se as características químicas do solo, nas profundidades 0-10, 10-20 e $20-30 \mathrm{~cm}$. Os resultados mostraram efeitos significativos das leguminosas sobre a fertilidade do solo, em comparação com a testemunha, com incrementos significativos de $\mathrm{pH}$ e de cátions trocáveis, refletindo positivamente na CTC e no índice de saturação por bases. Na matéria orgânica não ocorreu efeito significativo entre leguminosas e testemunha.

Palavras-chave: manejo de solo, fertilidade do solo, adubação verde, recuperação química de solo

\section{Effect of leguminous crops on the chemical characteristics and organic matter of a degraded soil}

\begin{abstract}
With the purpose of evaluating the effect of leguminous crops on the chemical characteristics of a degraded Alfisol, in the municipal district of Alagoinha, PB, Brazil, an experiment was conducted during 1997-99 with twelve species: Crotalaria juncea L, Cajanus cajan L, Cajanus cajan (L) Millsp, Calopogonium mucunoides L, Canavalia ensiformis L, Dolichos lab lab L, Pueraria phaseoloides L, Macroptilium atropurpureum L, Leucaena leucocephala L, Clitoria ternatea L, Styzolobium aterrimum $\mathrm{L}$, and Styzolobium cinereum Piper and Tracy besides a control treatment. In this study, the soil of the experimental site did not receive mineral fertilizer nor any corrective. The chemical characteristics of the soil were evaluated at 0-10, $10-20$ and $20-30 \mathrm{~cm}$ depths. The results showed significant effects of the leguminous crop on the fertility of the soil, in comparison to control, with significant increments of $\mathrm{pH}$ and of exchangeable bases, reflecting positively in CEC and in the base saturation. In the organic matter, there was no significant effect among the leguminous crops and control.
\end{abstract}

Key words: soil management, soil fertility, green manure, chemical recovery of soil

\section{INTRODUÇÃO}

As características físicas, químicas e biológicas de um solo sob cultivo, são por demais afetadas, o que promove alterações drásticas tanto na camada arável quanto nas subjacentes, sendo que os nutrientes e teor de matéria orgânica, por sua vez, tendem a diminuir a medida em que aumenta o tempo de cultivo, atribuído principalmente à erosão (Greenland, 1981). Ademais, Ros \& Aita (1996) afirmam que pela erosão ocorrem perdas expressivas de solo e nutrientes, sendo o nitrogênio o elemento mais afetado nesse processo, o que provoca limitações da produtividade das culturas, em face da principal fonte desse elemento no solo ser a matéria orgânica da camada superficial, a qual sofre perda seletiva durante a erosão hídrica.

Portanto, o nível de matéria orgânica do solo é um dos principais fatores condicionantes da sua produtividade e equilíbrio do sistema e, segundo Bouma \& Hole (1971) a taxa de sua decomposição é dependente, de certa forma, das práticas de cultivo empregadas, principalmente das relacionadas ao seu sistema e à incorporação de restos culturais. 
Neste sentido, sistemas de cultivo eficiente visando à diminuição do processo erosivo do solo, recuperação e manutenção de sua fertilidade, são buscados regionalmente, e o mais promissor é o sistema alternativo com o uso de espécies de plantas de cobertura do solo com potencial de proteção (Aita et al., 2001).

A região Nordeste do Brasil se caracteriza por sua alta densidade de pequenos e médios agricultores, onde a prática de agricultura de sequeiro é predominante com culturas anuais de subsistência e criações diversas, mantidas nas mesmas áreas sob cultivos. Nessas propriedades registram-se baixas produtividades, influenciadas sobremaneira pela irregularidade climática, cujo déficit de água no solo e seu manejo inadequado, são os fatores que mais limitam os rendimentos.

Em função das características climáticas observadas na região, os cultivos agrícolas são concentrados no único período chuvoso do ano, de fevereiro a junho, sendo que no período seco grande parte da área fica abandonada, ou em pousio, servindo a resteva para o pastejo animal, e sujeita à erosão, lixiviação de nutrientes e exposição à proliferação de ervas daninhas. Todos esses fatores, isolados ou em conjunto, contribuem fortemente para aumentar a degradação do solo, seja pela redução dos teores de nutrientes ou pela diminuição da atividade biológica e da matéria orgânica, pois a vegetação nativa ocorrente neste período não é suficientemente capaz de lhe fornecer proteção eficiente. De acordo com Sampaio \& Salcedo (1997) a diminuição da matéria orgânica no semi-árido nordestino ocorre pela retirada de nutrientes pelas culturas, pela erosão, por lixiviação e pela queima dos restos culturais, quando da sua implantação.

Sistemas de manejo em rotação de culturas com adubos verdes são eficientes no aumento do teor de carbono orgânico do solo (Vitti et al., 1979; Nascimento et al., 1981) além da proteção que estas exercem contra os efeitos da erosão, proporcionam maior retenção de água e menor variabilidade térmica do solo. Por sua vez, Heinrichs (1996) afirma que o uso de adubação verde é uma prática viável por contribuir para o restabelecimento do equilíbrio do sistema e, conseqüentemente, aumento da produtividade. Para Sarrantonio \& Scott (1988) e Tanaka (1981) os adubos verdes são importantes para a reciclagem de nutrientes, por produzirem grandes quantidades de fitomassa por área e por se apresentarem com concentrações elevadas de nutrientes na matéria seca da parte aérea, influenciada pela eficiência de seu sistema radicular em recuperar os nutrientes lixiviados para as camadas mais profundas do solo.

Diniz et al. (2002) avaliaram, no nordeste do Brasil, cultivos sucessivos de espécies de leguminosas e gramíneas durante três anos, em um Nitossolo Vermelho no Estado da Paraíba, concluindo que a leguminosa siratro proporcionou os maiores benefícios na produtividade do milho. Aita et al. (2001) estudando o potencial de plantas de cobertura de solo para o fornecimento de nutrientes, rela-taram maior eficiência das espécies de leguminosas em acumular nitrogênio na parte aérea, quando comparadas com as espécies de gramíneas.

Desta forma, pesquisas com espécies de leguminosas para uso como adubo verde nas condições edafoclimáticas do nordeste brasileiro ainda são restritas, fazendo-se necessário, entretanto, ampliar o estudo na busca por espécies de plantas adaptadas à região, com grande capacidade de sobrevivência nos períodos críticos e potencial para contribuírem com maior eficiência na proteção e regeneração da fertilidade do solo.

Por conseguinte, considerando-se a importância do cultivo de leguminosa no manejo do solo e no conteúdo da matéria orgânica, este trabalho teve como objetivo avaliar o efeito do cultivo de doze espécies nas características químicas de um Luvissolo degradado em Alagoinha, PB.

\section{MATERIAL E MÉTODOS}

O presente ensaio foi instalado na área experimental da Empresa Estadual de Pesquisa Agropecuária da Paraíba (EMEPA-PB) localizada no município de Alagoinha, PB, em solo classificado como Luvissolo Crômico Pálico abrupto (EMBRAPA, 1999), de textura franco-arenosa, fase floresta subcaducifólia, relevo (local) suave ondulado, com declividade (local) de $7 \%$ e altitude de $140 \mathrm{~m}$. Segundo a classificação de Köppen, o clima é do tipo As', com chuvas distribuídas nos períodos de outono e inverno, região bioclimática $3 \mathrm{dth}$ nordestino sub-seco (Brasil, 1972).

A área experimental foi cultivada durante dez anos com as culturas da cana-de-açúcar, feijão, milho, mandioca e gergelim, em sistema de rotação em agricultura de sequeiro e em caráter de subsistência, sendo que nesse sistema a cultura da canade-açúcar permaneceu na área por maior tempo (quatro anos) e com preparo de solo convencional. Nos anos de uso, o solo não recebeu corretivo nem adubação mineral.

A partir de abril de 1997 foi instalado o experimento, plantando-se doze espécies de leguminosas: guandu (Cajanus cajan, L.), guandu anão (Cajanus ca jan L. Millsp), lab-lab (Dolichos lab-lab, L.), mucuna preta (Styzolobium aterrimum, L.), cunhã (Clitoria ternatea L.), calopogônio (Calopogonium mucunoides, L), mucuna cinza (Styzolobium cinereum Piper e Tracy), siratro (Macroptilium atropurpureum, L), crotalária (Crotalaria juncea, L.), feijão-de-porco (Canavalia ensiforme, L.), kudzu tropical (Pueraria phaseoloides, L.) e leucena (Leucaena leucocephala, L.). Essas leguminosas foram semeadas em parcelas de $20 \mathrm{~m}^{2}(5 \mathrm{x} 4 \mathrm{~m})$ sob espaçamento de $0,5 \mathrm{~m}$ entre fileiras e $0,25 \mathrm{~m}$ entre plantas.

Nos anos de cultivo de 1998 e 1999, houve renovação da cobertura vegetal das parcelas a cada início do período chuvoso do ano (abril), por meio de semeadura das espécies leguminosas, semeadura natural ou replantios, com exceção da leucena que, no ciclo de 1999, foi podada apenas a $20 \mathrm{~cm}$ do solo. A biomassa das leguminosas remanescentes de cultivos anteriores foi manejada, deixando-se na superfície de suas respectivas parcelas, servindo de cobertura morta. Entretanto, no final do ciclo do cultivo de 1997 a biomassa proveniente das leguminosas lab-lab, mucuna preta, mucuna cinza e da crotalária, foi incorporada às suas respectivas parcelas. Durante o experimento, as leguminosas não receberam qualquer tipo de adubação mineral nem corretivo.

O delineamento experimental utilizado foi o de blocos casualizados, em esquema de parcela subdividida, com 13 tratamentos principais representados por doze espécies de 
leguminosas e testemunha (parcelas), e três tratamentos secundários, representados pelas profundidades (subparcelas), com três repetições. Como tratamento testemunha considerouse uma área sem cultivo, com vegetação espontânea rala. Os dados obtidos foram submetidos à análise de variância e suas médias contrastadas mediante o teste Tukey $(\mathrm{p}<0,05)$.

A coleta da amostra de solo para a caracterização química da área experimental foi realizada no final do ciclo das leguminosas (novembro de 1999). A amostra composta foi representada por três subamostras coletadas nas profundidades de 0-10, 10-20 e 20-30 cm. Em laboratório, o material, após secagem à sombra e ao ar por aproximadamente $72 \mathrm{~h}$ foi destorroado e passado em peneira de $2 \mathrm{~mm}$ de diâmetro, para procedimento das análises químicas.

$\mathrm{O} \mathrm{pH}$ foi determinado utilizando-se a suspensão solo-água na proporção de 1:2,5, o teor de carbono orgânico e os de fósforo $(\mathrm{P})$, de potássio $\left(\mathrm{K}^{+}\right)$, de cálcio $\left(\mathrm{Ca}^{++}\right)$, de magnésio $\left(\mathrm{Mg}^{++}\right)$, de alumínio $\left(\mathrm{Al}^{+++}\right)$, de acidez potencial $\left(\mathrm{H}^{+}+\mathrm{Al}^{+++}\right)$, da soma de bases (SB), da capacidade de troca cátions (CTC) e da saturação por bases (V) foram determinados segundo EMBRAPA (1997). Determinaram-se, ainda, as análises granulométricas (Forsythe, 1975) do solo da área experimental na profundidade estudada de 0-30 $\mathrm{cm}$ constatando-se, entre esses componentes, maior teor da fração areia $\left(637,56 \mathrm{~g} \mathrm{~kg}^{-1}\right)$, seguida da fração silte $\left(229,26 \mathrm{~g} \mathrm{~kg}^{-1}\right)$ e da fração argila $(133,18$ $\mathrm{g} \mathrm{kg}^{-1}$ ), conferindo-lhe a classificação textural franco-arenosa (Lemos \& Santos, 1996).

\section{RESULTADOS E DISCUSSÃO}

Do resultado das análises de variância relativo às características químicas do solo experimental em função dos tratamentos aplicados, constatou-se, efeito significativo isolado da profundidade sobre as características matéria orgânica (MO), fósforo $(\mathrm{P})$, cálcio $\left(\mathrm{Ca}^{++}\right)$, soma de bases $(\mathrm{SB})$, capacidade de troca de cátions (CTC), enquanto sobre o $\mathrm{pH}$, potássio $\left(\mathrm{K}^{+}\right)$, magnésio $\left(\mathrm{Mg}^{++}\right)$, saturação por base $(\mathrm{V})$ e acidez potencial $\left(\mathrm{H}^{+}+\mathrm{Al}^{+++}\right)$, verificou-se efeito significativo da interação (Leguminosas + Testemunha $\mathrm{x}$ Profundidade). Em relação à variação do teor de alumínio trocável $\left(\mathrm{Al}^{+++}\right)$, não houve efeito significativo entre leguminosas + testemunha e profundidades.

Em relação ao teor de $\mathrm{Al}^{+++}$do solo, embora constatado efeito não significativo pela análise, ressalta-se que o teor deste elemento no tempo e nas condições de uso do solo, foi mantido em nível baixo, variando em valores absolutos de 0,05 a 0,12 $\mathrm{cmol}_{\mathrm{c}} \mathrm{dm}^{-3}$. Esta variação entre leguminosas + testemunha e profundidades é tolerada pelas plantas (Tomé Júnior, 1997).

Para as características em que se constatou, pela análise, efeito significativo isolado em função da profundidade, o resultado da aplicação do teste de Tukey $(\mathrm{p}<0,05)$ é mostrado na Tabela 1, na qual se verifica, nos valores médios relativos às profundidades para a característica matéria orgânica do solo (MO) que o da profundidade de $0-10 \mathrm{~cm}$ foi considerado significativamente superior $\left(11,63 \mathrm{~g} \mathrm{~kg}^{-1}\right)$ aos demais valores das profundidades de $10-20 \mathrm{~cm}\left(10,75 \mathrm{~g} \mathrm{~kg}^{-1}\right)$ e de $20-30 \mathrm{~cm}$ $\left(8,77 \mathrm{~g} \mathrm{~kg}^{-1}\right)$ evidenciando-se, ainda nesta seqüência, tendência de diminuição com o aumento da profundidade, influenciado pelo maior acúmulo do resíduo vegetal na camada superficial do solo. Embora a profundidade de 0 - $10 \mathrm{~cm}$ seja considerada significativamente superior às demais, registrou-se um valor médio de baixa magnitude para esta característica enfatizandose, com este resultado, baixa eficiência das leguminosas estudadas nos três anos de uso, para o incremento da matéria orgânica do solo quando comparadas com a testemunha.

Tabela 1. Valores médios das características químicas do solo, onde ocorreu significância isolada da profundidade*

\begin{tabular}{cccccc}
\hline \multirow{2}{*}{$\begin{array}{c}\text { Profundidade } \\
(\mathrm{cm})\end{array}$} & $\begin{array}{c}\mathrm{MO} \\
\mathrm{g} \mathrm{kg}^{-1}\end{array}$ & $\begin{array}{c}\mathrm{P} \\
\mathrm{mg} \mathrm{dm}\end{array}$ & \multicolumn{4}{c}{$\mathrm{cmol}_{\mathrm{c}} \mathrm{dm}^{-3}$} \\
\cline { 2 - 6 } \cline { 4 - 6 } & $11,63 \mathrm{~A}$ & $2,97 \mathrm{~A}$ & $2,43 \mathrm{~B}$ & $4,31 \mathrm{~B}$ & $7,29 \mathrm{~B}$ \\
$00-10$ & $10,75 \mathrm{~B}$ & $1,55 \mathrm{~B}$ & $2,74 \mathrm{~A}$ & $4,73 \mathrm{~A}$ & $7,75 \mathrm{~A}$ \\
$10-20$ & $8,77 \mathrm{C}$ & $1,15 \mathrm{C}$ & $2,77 \mathrm{~A}$ & $4,61 \mathrm{~A}$ & $6,98 \mathrm{~B}$ \\
\hline $20-30$ & 0,54 & 0,19 & 0,16 & 0,26 & 0,31 \\
\hline
\end{tabular}

*Médias seguidas pela mesma letra na coluna não diferem $(\mathrm{p}<0,05)$ pelo teste de Tukey. Características: MO, matéria orgânica; $\mathrm{P}$, fósforo; $\mathrm{Ca}$, cálcio; $\mathrm{SB}$, soma de bases; CTC, capacidade de troca de cátions

Esta constatação decorre, provavelmente, de alguns fatores, como: declividade local, clima, grande variação de temperatura e umidade (local) favorecendo, com isto, uma rápida decomposição, tendo em vista a baixa relação $\mathrm{C} / \mathrm{N}$ do tecido vegetal dessas espécies; textura do solo franco-arenoso, a qual apresenta alta vulnerabilidade ao processo erosivo, e influência do manejo do material vegetal, por não se considerar a melhor época e também por ser realizado de forma manual.

Entre os valores médios de $\mathrm{P}$ do solo entre profundidades (Tabela 1), constatou-se que o da profundidade de $0-10 \mathrm{~cm}$ $\left(2,97 \mathrm{mg} \mathrm{dm}^{-3}\right)$ foi significativamente superior $(\mathrm{p}<0,05)$ aos da profundidade de $10-20 \mathrm{~cm}\left(1,55 \mathrm{mg} \mathrm{dm}^{-3}\right)$ e de $20-30 \mathrm{~cm}$ $\left(1,15 \mathrm{mg} \mathrm{dm}^{-3}\right)$. O acúmulo deste nutriente na camada superficial do solo é resultante de sua liberação em maior quantidade da decomposição dos resíduos vegetais e diminuição da sua fixação, em decorrência do menor contato desse elemento com os constituintes do solo (Sidiras \& Pavan, 1985). Entretanto, tais valores observados são considerados baixos e com tendência de diminuição, à medida que se aprofundam, no perfil, resultados que refletem a limitada mobilidade desse elemento no solo (Muzilli, 1981 e 1983). Isto se evidencia claramente neste experimento, ao se observar estreita relação direta dos níveis desse nutriente nas profundidades estudadas do solo com os de matéria orgânica.

Com relação aos teores $\mathrm{Ca}^{++}$entre profundidades (Tabela 1), concluiu-se que o valor da profundidade de $0-10 \mathrm{~cm}(2,43$ $\left.\mathrm{cmol}_{\mathrm{c}} \mathrm{dm}^{-3}\right)$ foi significativamente inferior ao das profundidades de $10-20 \mathrm{~cm}\left(2,74 \mathrm{cmol}_{\mathrm{c}} \mathrm{dm}^{-3}\right)$ e de $20-30 \mathrm{~cm}\left(2,77 \mathrm{cmol}_{\mathrm{c}} \mathrm{dm}^{-3}\right)$, sendo estes iguais entre si $(\mathrm{p}<0,05)$. Embora os referidos valores de $\mathrm{Ca}^{++}$estejam em nível considerado razoável para as culturas observou-se, na condição experimental de solo e clima, baixa eficiência das leguminosas em reciclar este nutriente do solo, quando comparado com a testemunha. Estes resultados concordam, em parte, com os de Lourenço et al. (1993), quando relataram que a incorporação de restos vegetais de leguminosas como guandu, kudzu tropical, mucuna preta e leucena, não contribuíram para elevar o teor desse nutriente no solo.

Para as características SB e CTC na Tabela 1 constatou-se, em seus valores, que o da profundidade de $10-20 \mathrm{~cm}$ foi 
significativamente superior $(\mathrm{p}<0,05)$ ao das outras profundidades. Vê-se que tais resultados estão em consonância com os relatados para o $\mathrm{Ca}^{++}$do experimento, o que se deve ao fato de que o nível de $\mathrm{Ca}^{++}$no solo influencia diretamente os valores de SB e CTC, por fazer parte de suas determinações (EMBRAPA, 1997).

Dos resultados das análises dos desdobramentos leguminosas + testemunha dentro de profundidade das interações significativas constatou-se para o $\mathrm{pH}$ do solo, efeito significativo $(\mathrm{p}<0,01)$ entre leguminosas + testemunha nas três profundidades estudadas, enquanto para as características $\mathrm{K}^{+}, \mathrm{Mg}^{++}, \mathrm{H}^{+}+\mathrm{Al}^{+++} \mathrm{e} \mathrm{V}$, diferiram significativamente apenas na profundidade de $0-10 \mathrm{~cm}$.

Para o $\mathrm{pH}$ do solo, a Tabela 2 mostra os valores médios das leguminosas + testemunha relativas às três profundidades estudadas resultantes da aplicação do teste de média Tukey $(\mathrm{p}<0,05)$. Verificou-se, entre os valores médios, que os das leguminosas foram significativamente superiores $(\mathrm{p}<0,05)$ ao da testemunha nas três profundidades, de $0-10 \mathrm{~cm}$, de $10-20$ $\mathrm{cm}$ e de $20-30 \mathrm{~cm}$ (Tabela 2), cujos resultados indicam efeito positivo do cultivo das leguminosas nas condições de estudo do experimento, proporcionando diminuição considerável de sua acidez em todas as profundidades estudadas. Tal efeito pode ser atribuído à ação das leguminosas: quanto à cobertura vegetal, pelo retorno dos seus resíduos ao solo; em relação ao sistema radicular, pela maior concentração de raízes no perfil e, neste caso, favorecendo absorção maior de alguns nutrientes, principalmente dos teores trocáveis de $\mathrm{Ca}^{++}, \mathrm{Mg}^{++} \mathrm{e} \mathrm{K}^{+}$, o que proporciona melhorias na SB e na CTC dos solos e, desta forma, pode contribuir para uma eficiência maior da reciclagem desses nutrientes, sobretudo os de $\mathrm{Mg}^{++}$e $\mathrm{K}^{+}$, constatado neste experimento na superfície do solo (Tabela 3). Resultados semelhantes foram encontrados por Alcântara (1998), Pequeno (1999) e Ribeiro (1999). Neste sentido, Wade \& Sanchez (1983) e Sidiras \& Pavan (1985) observaram a influência de algumas práticas de manejo do solo usando adubação verde em sucessão às culturas no aumento significativo do $\mathrm{pH}$ do solo, atribuído à cobertura vegetal com o retorno de seus resíduos na superfície do solo.

Tabela 2. Valores médios de $\mathrm{pH}$ do solo sob leguminosas e testemunha. em função da profundidade

\begin{tabular}{|c|c|c|c|}
\hline \multirow{2}{*}{ Tratamentos } & \multicolumn{3}{|c|}{$\mathrm{pH}(\mathrm{cm})$} \\
\hline & $0-10$ & $10-20$ & $20-30$ \\
\hline Testemunha & $5,23 \mathrm{C}$ & $5,17 \mathrm{C}$ & $5,37 \mathrm{~B}$ \\
\hline Guandu & $5,70 \mathrm{ABC}$ & $5,67 \mathrm{AB}$ & $5,67 \mathrm{AB}$ \\
\hline Guandu-anão & $5,60 \mathrm{ABC}$ & $5,60 \mathrm{ABC}$ & $5,67 \mathrm{AB}$ \\
\hline Lab-lab & $5,53 \mathrm{ABC}$ & $5,37 \mathrm{BC}$ & $5,40 \mathrm{AB}$ \\
\hline Mucuna preta & $5,53 \mathrm{ABC}$ & $5,43 \mathrm{ABC}$ & $5,50 \mathrm{AB}$ \\
\hline Cunha & $5,93 \mathrm{~A}$ & 5,63 ABC & $5,63 \mathrm{AB}$ \\
\hline Calopogônio & $5,70 \mathrm{ABC}$ & $5,50 \mathrm{ABC}$ & $5,43 \mathrm{AB}$ \\
\hline Mucuna cinza & $5,50 \mathrm{ABC}$ & 5,57 ABC & $5,83 \mathrm{AB}$ \\
\hline Siratro & $5,90 \mathrm{~A}$ & $5,40 \mathrm{ABC}$ & $5,53 \mathrm{AB}$ \\
\hline Crotalária & $5,60 \mathrm{ABC}$ & $5,60 \mathrm{ABC}$ & $5,60 \mathrm{AB}$ \\
\hline Feijão-de-porco & $5,83 \mathrm{AB}$ & $5,43 \mathrm{ABC}$ & $5,50 \mathrm{AB}$ \\
\hline Kudzu tropical & $5,37 \mathrm{BC}$ & $5,47 \mathrm{ABC}$ & $5,70 \mathrm{AB}$ \\
\hline Leucena & $5,83 \mathrm{AB}$ & $5,87 \mathrm{~A}$ & $5,87 \mathrm{~A}$ \\
\hline DMS & 0,48 & 0,48 & 0,48 \\
\hline
\end{tabular}

Médias seguidas pela mesma letra na coluna não diferem $(\mathrm{P}<0,05)$ pelo teste de Tukey
Na Tabela 3 encontram-se os valores médios das leguminosas + testemunha relativas às características $\mathrm{K}^{+}, \mathrm{Mg}^{++}$, $\mathrm{H}^{+}+\mathrm{Al}^{+++}$e de $\mathrm{V}$ do solo na profundidade de $0-10 \mathrm{~cm}$. Dos resultados de $\mathrm{K}^{+}$observou-se, entre tratamentos, alta variação de seus valores médios, sendo que os dos tratamentos leguminosas foram considerados significativamente $(\mathrm{p}<0,05)$ superiores ao da testemunha, com destaque para as leguminosas mucuna preta, cunhã, crotalária e leucena, com os maiores valores em ordem decrescente (Tabela 3). Estes resultados mostram também efeitos positivos das leguminosas com aumentos significativos do teor desse elemento na camada de $0-10 \mathrm{~cm}$, referindo-se como de fundamental importância na sua reciclagem. Ainda segundo Eltz et al. (1989) os teores deste nutriente no perfil do solo tendem a decrescer com a profundidade, acompanhando os níveis de matéria orgânica. Maior concentração desse nutriente na camada superficial do solo também foi observada por Muzilli (1983), por Peixoto \& Eltz (1986) e por Eltz et al. (1989) quando estudaram diferentes sistemas de manejo. Lourenço et al. (1993) estudando o comportamento da mucuna preta, kudzu tropical, guandu e leucena, relataram que estas apresentaram tendência de extraírem o potássio do solo em maiores quantidades, comparado com os outros nutrientes.

Tabela 3. Valores médios das características químicas do solo sob leguminosas e testemunha em função da profundidade de $0-10 \mathrm{~cm}^{*}$

\begin{tabular}{|c|c|c|c|c|}
\hline \multirow{3}{*}{ Tratamentos } & \multicolumn{4}{|c|}{ Características do Solo } \\
\hline & \multirow{2}{*}{$\underset{\mathrm{mg} \mathrm{dm}}{\mathrm{K}}$} & $\mathrm{Mg}$ & $\mathrm{H}+\mathrm{Al}$ & \multirow{2}{*}{$\begin{array}{l}\mathrm{V}^{1} \\
\%\end{array}$} \\
\hline & & \multicolumn{2}{|c|}{$\mathrm{cmol}_{\mathrm{c}} \mathrm{dm}^{-3}$} & \\
\hline Testemunha & $43,33 \mathrm{~B}$ & $1,03 \mathrm{AB}$ & $3,41 \mathrm{~A}$ & $51,93 \mathrm{C}$ \\
\hline Guandu & $80,83 \mathrm{AB}$ & $1,77 \mathrm{AB}$ & $3,14 \mathrm{~A}$ & $57,62 \mathrm{ABC}$ \\
\hline Guandu-anão & $78,33 \mathrm{AB}$ & $1,43 \mathrm{AB}$ & $2,92 \mathrm{~A}$ & $58,37 \mathrm{ABC}$ \\
\hline Lab-lab & $95,00 \mathrm{AB}$ & $2,20 \mathrm{~A}$ & $2,92 \mathrm{~A}$ & $63,27 \mathrm{AB}$ \\
\hline Mucuna preta & $112,50 \mathrm{~A}$ & $1,37 \mathrm{AB}$ & $3,41 \mathrm{~A}$ & $55,25 \mathrm{ABC}$ \\
\hline Cunha & $110,17 \mathrm{~A}$ & $2,07 \mathrm{AB}$ & $2,56 \mathrm{~A}$ & $62,41 \mathrm{ABC}$ \\
\hline Calopogônio & $67,50 \mathrm{AB}$ & $1,70 \mathrm{AB}$ & $3,08 \mathrm{~A}$ & $58,63 \mathrm{ABC}$ \\
\hline Mucuna cinza & $60,00 \mathrm{AB}$ & $0,53 \mathrm{~B}$ & $3,36 \mathrm{~A}$ & $52,18 \mathrm{BC}$ \\
\hline Siratro & $86,83 \mathrm{AB}$ & $1,80 \mathrm{AB}$ & $2,53 \mathrm{~A}$ & $64,40 \mathrm{~A}$ \\
\hline Crotalária & $108,33 \mathrm{~A}$ & $2,00 \mathrm{AB}$ & $3,03 \mathrm{~A}$ & $60,35 \mathrm{ABC}$ \\
\hline Feijão-de-porco & $97,50 \mathrm{~A}$ & $1,57 \mathrm{AB}$ & $2,81 \mathrm{~A}$ & $61,88 \mathrm{ABC}$ \\
\hline Kudzu tropical & $84,17 \mathrm{AB}$ & $1,30 \mathrm{AB}$ & $3,19 \mathrm{~A}$ & $55,71 \mathrm{ABC}$ \\
\hline Leucena & $101,83 \mathrm{~A}$ & $1,73 \mathrm{AB}$ & $2,42 \mathrm{~A}$ & $65,13 \mathrm{~A}$ \\
\hline DMS & 53,87 & 1,61 & 1,13 & 11,18 \\
\hline
\end{tabular}

"Médias seguidas pela mesma letra na coluna, não diferem entre $(\mathrm{P}<0,05)$ pelo teste de Tukey Saturação de bases (\%)

Para o nutriente $\mathrm{Mg}^{++}$do solo (Tabela 3), entre os valores médios observou-se, para a leguminosa lab-lab, valor significativamente superior $\left(2,2 \mathrm{cmol}_{\mathrm{c}} \mathrm{dm}^{-3}\right)$, seguido da cunhã $(2,07$ $\left.\mathrm{cmol}_{\mathrm{c}} \mathrm{dm}^{-3}\right)$ e da crotalária $\left(2,00 \mathrm{cmol}_{c} \mathrm{dm}^{-3}\right)$, enquanto para a testemunha o valor médio foi de $1,03 \mathrm{cmol}_{c} \mathrm{dm}^{-3}$, e para o tratamento mucuna cinza, o valor foi significativamente inferior $\left(0,53 \mathrm{cmol}_{\mathrm{c}} \mathrm{dm}^{-3}\right)$. De maneira geral, tais resultados comprovam também que as leguminosas acima mencionadas são importantes na reciclagem deste nutriente, em níveis satisfatórios para a cultura subseqüente, resultados também verificados por Alcântara (1998) e Pequeno (1999).

Em relação à característica acidez potencial do solo dos tratamentos $\left(\mathrm{H}^{+}+\mathrm{Al}^{+++}\right)$, embora significativo pelo teste $\mathrm{F}$ na 
respectiva camada estudada (Tabela 3) verificou-se, entre suas médias que, quando comparadas entre si pelo teste Tukey ( $p<0,05)$, não foi possível se estabelecer tais diferenças pelo referido teste. Entretanto, observa-se variação de 2,42 $\mathrm{cmol}_{\mathrm{c}}$ $\mathrm{dm}^{-3}$ para a leguminosa leucena, a $3,41 \mathrm{cmol}_{\mathrm{c}} \mathrm{dm}^{-3}$, para a leguminosa mucuna preta e testemunha (Tabela 3)

Quanto ao índice de saturação por bases (V) na profundidade de $0-10 \mathrm{~cm}$ (Tabela 3 ) notou-se entre os valores médios dos tratamentos, uma variação de $51,93 \%$ para a testemunha, a $65,13 \%$ para a leguminosa leucena, evidenciando que todos os valores dos tratamentos representados pelas leguminosas foram significativamente superiores ao da testemunha $(\mathrm{p}<0,05)$. Analisando-se esses resultados, conclui-se que as leguminosas leucena, siratro, lab-lab, cunhã, feijão-de-porco e crotalária, em ordem decrescente de valores percentuais, contribuíram de forma eficiente para elevar o nível deste índice na profundidade estudada, acima de 60\%. Segundo Tomé Júnior (1997) este índice fornece informações a respeito do total de cargas negativas existentes no solo e também apresenta uma idéia sobre a proporção ocupada pelos cátions $\mathrm{Ca}^{++}, \mathrm{Mg}^{++}$e $\mathrm{K}^{+}$, servindo como base para a avaliação da fertilidade do solo.

\section{CONCLUSÕES}

1. Os teores de matéria orgânica do solo apresentaram-se baixos e não refletiram nos efeitos dos tratamentos.

2. As leguminosas contribuíram para diminuir a acidez do solo, elevando o $\mathrm{pH}$ no perfil estudado.

3. Os maiores efeitos das leguminosas na elevação dos teores de nutrientes no solo dizem respeito ao potássio e ao magnésio, na profundidade de $0-10 \mathrm{~cm}$.

\section{LITERATURA CITADA}

Aita, C.; Basso, C.J.; Ceretta, C.A.; Gonçalves, C.N.; Ros, C.O. da. Plantas de cobertura de solo como fonte de nitrogênio ao milho. Revista Brasileira de Ciência do Solo. Viçosa, v.25, p.157-165, 2001.

Alcântara, F.A. de. Adubação verde na recuperação da fertilidade de um solo degradado. Lavras: UFLA, 1998. 104p. Dissertação Mestrado

Bouma, J.; Hole, F.D. Soil structure and hydraulic conductivity of adjacent virgin and cultivated pedons at two sites: A typic argiudoll (silt loam) and a typic eutrochrept (clay). Proceedings Soil Science Society of America, Madison, v.35, p.316-319. 1971.

Brasil, Ministério da Agricultura. I. Levantamento exploratório - Reconhecimento de solos do Estado da Paraíba. II. Interpretação para uso agrícola dos solos do Estado da Paraíba. Rio de Janeiro: MA/CONTAP/USAID/SUDENE. 1972. 637 p. BRASIL-MA. Boletim Técnico, 8. Série Pedologia, 8

Diniz, B.L.M.T.; Silva, I.F.; Rego, P.R.A.; Diniz Neto, M.A. Avaliação da produtividade do milho em função da adubação verde. Agropecuária Técnica, Areia, v.23, n.1/2, p.57-62, 2002
Eltz, F.L.F.; Peixoto, R.T.G.; Jaster, F. Efeito de sistemas de preparo do solo nas propriedades químicas de um Latossolo Bruno álico. Revista Brasileira de Ciência do Solo, Campinas, v.13, p.259-267. 1989.

EMBRAPA - Empresa Brasileira de Pesquisa Agropecuária. Manual de métodos de análise de solo. 2. ed. Rio de Janeiro, 1997.212p.

EMBRAPA - Empresa Brasileira de Pesquisa Agropecuária. Sistema brasileiro de classificação de solos. Brasília: Produções de Informações, 1999. 412p.

Forsythe, W.M. Fisica de suelos: Manual de laboratorio. San Jose: Instituto Interamericano de Ciencias Agricolas, 1975. 212p.

Greenland, D.J. Soil management and soil degradation. Journal of Soil Science, Reading, v.32, p.301-322. 1981.

Heinrichs, R. Ervilhaça e aveia preta cultivadas simultaneamente como adubo verde e sua influência no rendimento do milho. Piracicaba: ESALQ, 1996. 65p. Dissertação Mestrado

Lemos, R. C.; Santos, R.D. dos. Manual de descrição e coleta de solo no campo. 3. ed. Campinas: SBCS/CNPS, 1996. 84p.

Lourenço, A.J.; Matsui, E.; Delistoianoy, J.; Boin, C.; Bortoleto, O. Efeito de leguminosas tropicais na matéria orgânica do solo e na produtividade do sorgo. Revista Brasileira de Ciência do Solo, Campinas, v.17, p.263-268. 1993.

Muzilli, O. Manejo da fertilidade do solo. In: Plantio direto no Paraná. Londrina: Fundação Instituto Agronômico do Paraná, 1981. p.43-57. Circular, 23

Muzilli, O. Influência do sistema de plantio direto, comparado ao convencional sobre a fertilidade da camada arável do solo. Revista Brasileira de Ciência do Solo, Campinas, v.7, p.95-102. 1983.

Nascimento, V.M.; Melo, W.J.; Buzetti, S. Efeito do desmatamento sobre o teor de matéria orgânica de um solo sob vegetação de cerrado cultivado com o milho (Zea mays L.), arroz (Oryza sativa L.) e soja (Glycine max (L.) Merril). Ilha Solteira: FE/UNESP, 1981. p.50-52. Relatório Técnico Científico, 1

Peixoto, R.T.G.; Eltz, P.L.F. Avaliação da fertilidade do solo em plantio direto na região dos Campos Gerais. Paraná. In: Reunião Brasileira de Fertilidade do Solo, 17. Londrina, PR, 1986. Resumo... Londrina: Sociedade Brasileira de Ciência do Solo, EMBRAPA e IAPAR. 1986. p.56-57.

Pequeno, P.L.L. Sistema radicular de leguminosas: Efeito nas propriedades físicas de um Podzólico Vermelho-Amarelo no município de Alagoinha, PB. Areia: UFPB, 1999. 52p. Dissertação Mestrado

Ribeiro, P.A. Utilização de leguminosas na produção de biomassa e como fonte de nutrientes em um Podzólico Vermelho-Amarelo no município de Alagoinha, PB. Areia: UFPB, 1999. 57p. Dissertação Mestrado

Ros, C.O.; Aita, C. Efeito de espécies de inverno na cobertura do solo e fornecimento de nitrogênio ao milho em plantio direto. Revista Brasileira de Ciência do Solo, Campinas, v.20, p.135-140, 1996.

Sampaio, E.V.S.B.; Salcedo, I.H. Diretrizes para o manejo sustentável dos solos brasileiros: Região semi-árida. Simpósio Diretrizes para o Manejo Sustentável dos Solos Brasileiros, Congresso Brasileiro de Ciência do Solo, 16. Anais...Rio de Janeiro: SBCS, 1997. CD ROM, 1997. 
Sarrantonio, M.; Scott, T.W. Tillage effects on availability of nitrogen to corn following a winter green manure crop. Soil Science Society of America Journal, Madison, v.52, p.16611668. 1988.

Sidiras, N.; Pavan, M.A. Influência do sistema de manejo do solo no seu nível de fertilidade. Revista Brasileira de Ciência do Solo. Campinas, 9:249-254, 1985.

Tanaka, R.T. Adubação verde. Informe Agropecuário, Belo Horizonte, v.7, p.62-67, 1981.
Tomé Júnior, B. Manual para interpretação de análise de solo. Guaíba: Agropecuária, 1997. 247p.

Vitti, G.C.; Ferreira, M.E.; Perecin, D.; Zanetti Neto, P. Influência de cinco leguminosas como adubo verde na fertilidade de um Latossolo Vermelho-Amarelo fase arenosa (LVa). Científica, São Paulo. v.7, n.3, p.431-435. 1979.

Wade, M.K.; Sanchez, P.A. Mulching green manure applications for continuous crop production in the amazon basin. Agronomy Journal, Madison, v.75, p.39-45, 1983. 